[PSY 10139]

\title{
BODY IMAGE AND ADOLESCENCE: BEHAVIORAL IMPAIRMENT MODEL
}

Cristina Senín-Calderón ${ }^{\mathrm{a}}$, Juan F. Rodríguez-Testab ${ }^{\mathrm{b}}$, Salvador Perona-Garcelán ${ }^{\mathrm{b}, \mathrm{c}}$, Conxa $\underline{\text { Perpiñã }^{\mathrm{d}, \mathrm{e}}}$

a. Department of Psychology, University of Cádiz, Spain; b. Personality, Evaluation and Psychological Treatment Department, University of Seville, Spain; c. Institute of Biomedicine, Seville, \& University Hospital Virgen del Rocío, Spain; d. University of $\underline{\text { Valencia, Spain }}$

a. Department of Psychology, University of Cádiz. Ave. República Árabe Saharaui s/n, 11519 $\underline{\text { Puerto Real (Cádiz, Spain) cristina.senin@uca.es }}$

b. Personality, Evaluation and Psychological Treatment Department. St. Camilo José Cela s/n, 41018 Seville (Spain). testal@us.es

c. University Hospital Virgen del Rocío. Ave. Manuel Siurot, s/n, 41013 Seville (Spain). sperona@us.es

d. Universidad de Valencia, Valencia, Spain. Concepcion.Perpina@uv.es

e. CIBER Fisiopatología Obesidad y Nutrición (CIBERobn), Instituto Salud Carlos III. 
*Corresponding author: PhD. Juan F. Rodríguez-Testal. Personality, Evaluation and

$\underline{\text { Psychological Treatment Department. St./ Camilo José Cela s/n, } 41018 \text { Seville (Spain). }}$

$\underline{\text { testal@us.es }}$

\title{
BODY IMAGE AND ADOLESCENCE: A BEHAVIORAL IMPAIRMENT MODEL
}

\begin{abstract}
Adolescence is a period marked by important physical and social changes that can lead to a negative body image. The purpose of this study was to find a model enabling the appearance of behavioral impairment related to body image (restrictions, avoidance, and checking) to be predicted by body image attitudes (concern or Appearance Orientation, and dissatisfaction or Appearance Evaluation), Gender, emotional symptomatology, self-consciousness, ideas of reference (IR) and age. A total of 661 participants (67.47\% girls) with an average age of 17.14 years $(S D=2.34)$ filled in the GHQ-28, SCS on self-consciousness, REF referential thinking scale, MBSRQ (AO and AE), and BIAQ. A partial mediation model was found for IR, age and depressive symptomatology between dissatisfaction and concern about body image and Gender, to behavioral impairment related to body image. The results found suggest that age, depressive symptomatology, and IR may be mediator variables in the relationship between dissatisfaction and concern about body image, on body image behavioral impairment. This relationship implies a severity to be considered in intervention and monitoring of body image behavioral impairments in adolescents.
\end{abstract}

Key words: body image concern, body image evaluation, adolescents, depressive symptoms, ideas of references, psychopathological risk 


\section{Introduction}

Body image is a stable multifaceted mental representation of our body and its emotional experience, which is continually being updated (Cash and Smolak, 2011; Pruzinsky, 2004; Rodríguez-Testal, 2013). During adolescence, concern about body image is frequent due to the succession of physical and cognitive changes taking place, so evaluation and focus on body and appearance increase (Littleton and Ollendick, 2003; Mitchell et al., 2012). Internalization of the ideal of beauty by sociocultural influences and social comparison facilitate development of a negative body image and unhappiness with appearance (Carey et al., 2014; Vartanian and Dey, 2013).

Body dissatisfaction begins to be relevant from 12-15 years of age (Levine and Smolak, 2002) and is a risk factor for eating disorders (Stice et al., 2011) and other maladapted behaviors (Delinsky and Wilson, 2006; Smolak, 2011), amplified by the frequent presence of depressive and anxiety symptoms (Hughes and Gullone, 2011; Markey, 2010). It is known that girls are more dissatisfied with their body image than boys throughout adolescence (Dion et al., 2015).

Cash and Smolak (2011) consider body image to be made up of two attitudes or dimensions. The first is self-evaluation (or appearance evaluation) in which the emotional component prevails, concentrating on pleasure/displeasure or satisfaction/dissatisfaction with appearance (body self-esteem). The effect of internalization of society's ideal of beauty shares

in this attitude. A second component of body image is an attitude investment in personal appearance (or appearance orientation). In this cognitive-behavioral dimension, care, attention and behavior related to the body are analyzed (functional component). Reference is made to a negative body image when both attitudes are present, causing dissatisfaction (more usual) and 
concern/overvaluing appearance, antechamber of body image impairment (Cash and Smolak, 2011; Rodríguez-Testal, 2013).

Body image is a part of our identity and development of our self-consciousness (Adams et al., 1987). It is created based on interaction with others and interiorized social valuation (Cash and Fleming, 2002; Tantleff-Dunn and Lindner, 2011). Adolescents are more prone to compare themselves with others and give much more importance to what others think about their appearance or how they look (Sebastian et al., 2008), favoring a strong tendency to selffocus (acute self-consciousness) and self-referencing, which Elkind and Bowen (1979) called "public or imaginary audience" (the characteristic adolescent egocentrism).

Strong self-focused attention, or pathological self-consciousness, is a process related to different impairments, from anxiety and depression to schizophrenia or psychopathy (Ingram, 1990). Fenigstein et al. (1975) differentiated between private self-consciousness and public self-consciousness. The first refers to attention to thoughts, emotions or beliefs, while the second is directed at one's look, physical appearance, impression on others, or a general consciousness of the self as a social object.

Ideas of reference (IR) or self-references are products of cognitive processing by which the subject self-attributes what happens in the social setting (usually negative connotation) (APA, 2013). IR are considered present at any time in the individual's development, can show a loss of adjustment to reality ("they put songs on the radio for me") and in relation to social interaction ("they look at me and laugh"). They have been described mainly in the area of psychopathology, especially if they are frequent and invasive, or when they are maintained with delusional conviction. They are considered typical symptoms of psychotic disorders in general, as well as paranoid personality or schizotypy disorders, or in social phobia (Lenzenweger et al., 1997; Raine, 1991). Therefore, IR are suggestive of a pathological 
situation because of their presence and because of one's evaluation of them, as suggested in various instruments (Brenner et al., 2007; Wong et al., 2012), and to differentiate pathologies (Senín-Calderón et al., 2014).

In brief, at this moment of change in adolescence, there are self-directed and self-relevant process related to body image, especially if it is problematic, which would make its transfer into an salient presence in public self-consciousness and IR expectable. Public selfconsciousness could be a more general pathological condition or process, and IR, a more specific pathological process (and product) related to social cognition (Senín-Calderón et al., 2014) which places the psychological balance of the adolescent at risk.

The purpose of this study was to examine the relationships of dissatisfaction or Appearance Evaluation (AE), concern or Appearance Orientation (AO) and Gender, with the behavioral impairments related to body image (restrictions, avoidance, and checking). It attempted to check the mediating role of IR, of private self-consciousness, public selfconsciousness and emotional symptomatology (anxiety and depression). We therefore proposed the following hypotheses:

1. A higher score in AO and low score on AE is related to a greater presence of IR, more emotional symptomatology (anxiety and depression) and more private and public selfconsciousness. Girls score higher on private self-consciousness, and anxiety and depressive symptomatology.

2. IR, private self-consciousness, public self-consciousness, and emotional symptomatology (anxiety and depression) are positively related to body image behavior impairment. 
3. The relationship between $\mathrm{AO}, \mathrm{AE}$ and Gender to body image behavioral impairment is mediated by IR, private self-consciousness, public self-consciousness, and emotional symptomatology (anxiety and depression).

\section{Methods}

\subsection{Participants and procedure}

The sample was composed of 661 young people (high school and college students); 215 men $(32.53 \%)$ and 446 women $(67.47 \%)$ who gave their written consent for participating in the study (or parents of minors). Their mean age was 17.14 years $(S D=2.34)$, age range 14 21. $99.8 \%$ of the participants were single. The social class index (according to Hollingshead, 1975) was from 11 (very high class) to 81 (very low class), with a mean total of 39.76 points (middle class; $S D=20.97$ ).

Participants were selected by non-random accessibility sampling. The participants filled in the self-report assessment tests in class in the order described under instruments.

\subsection{Instruments}

First self-reported evaluation (by authors). This identified the social class index (SCI) (Hollingshead, 1975), current illnesses, psychopathological antecedents, history and duration of symptoms, psychopharmacological treatments and use of other drugs.

Goldberg General Health Questionnaire (GHQ-28) Spanish version by Lobo et al. (1986). This is a screening test that gives an overall evaluation of health and social dysfunction. It consists of 28 items grouped in four subscales on somatic symptoms, anxiety, social dysfunction and severe depression. In this study, the anxiety and depression subscales were used. It has adequate reliability (test-retest, 0.90 ) and validity (sensitivity from $44 \%$ to $100 \%$ 
and specificity from $74 \%$ to $93 \%$ ). In this study, consistency for anxiety symptoms was $\alpha=$ 0.80 and depressive symptoms was $\alpha=0.70$.

Referential Thinking Scale (REF) (Lenzenweger et al., 1997). This 34-item true-or-false selfreport questionnaire on ideas of reference (IR) has an internal consistency of 0.83 to 0.85 , retest reliability of 0.86 (four-week interval), and adequate validity indicators. The scale provides a schizotypy indicator with saturation from 0.75 to 0.85 in principal component analysis, and to a lesser extent, for anxiety and depression (0.33 to 0.17$)$. The Spanish version of the REF scale has an $\alpha$ of up to 0.90 ( 0.83 and 0.82 on each half) and a retest $\alpha$ of 0.76 (average interval of 44 days in patients). The validity criterion (with regard to the clinical follow-up instrument BPRS) has a cutoff point of 7 with $66 \%$ specificity and $58 \%$ sensitivity (Senín-Calderón et al., 2010). In this study consistency was $\alpha=0.82$.

The Revised Self-consciousness Scale (Scheier and Carver, 1985), Spanish version by Banos et al. (1990) is made up of 22 items which evaluate the tendency of individuals to direct their attention outside or within themselves. It has three factors: 1) Private self-consciousness, 2) Public self-consciousness, and 3) social anxiety, which was not used in this study. It has adequate reliability $(\alpha$ Private self-consciousness $=0.75, \alpha$ Public self-consciousness $=0.92$, social anxiety $=0.81$, and validity (content and construct) indicators. In this study consistency was $\alpha=0.75$ for Private self-consciousness, and $\alpha=0.77$ for Public selfconsciousness.

The Body Image Avoidance Questionnaire (BIAQ; Rosen et al., 1991) consists of 19 items that assess avoidance behavior with respect to clothing, social activities, eating restraint, and grooming and weight. The authors of the instrument found high internal consistency (Cronbach's $\alpha=0.89$ ), reliability test-retest $=0.87$, adequate validity (correlation between 
BIAQ and $\mathrm{BSQ}=0.71$ ). In our study, the total score was used as the measure of behavioral impairment related to body image. Internal consistency was $\alpha=0.73$ for the whole scale.

The Multidimensional Body-Self Relations Questionnaire (MBSRQ, Cash, 2000), version by Raich et al. (1996), is a measure of the various aspects of body image. The version used for the study has six factors: [1] Interest in sports and physical aptitude, [2] concern or Appearance orientation, AO, [3] dissatisfaction or Appearance evaluation, AE, [4] Hypochondriac signs [5] Health assessment, and [6] Interest in health. Internal consistency was 0.96 , test-retest reliability and validity were adequate. This study used the AE and AO factors. Higher values on the AE subscale suggest satisfaction with one's own appearance. On the AO subscale, higher ratings indicate greater investment in own appearance and body care. The Cronbach's $\alpha$ for this study was 0.90 for AE and 0.87 for AO.

\subsection{Data analysis}

Descriptive analyses and comparison of means ( $t$ test $)$ were done. The variables analyzed (referring to the factors in the evaluation tests) were transformed into Z. Pearson's correlations of the scale factors were calculated, and then the mediation analysis was carried out. This analysis approaches the association and magnitude of the variables of a potential causal phenomenon (Hayes and Preacher, 2013). It starts out from a possible cause-effect relationship between an independent variable $\mathrm{X}(\mathrm{AO}, \mathrm{AE}, \mathrm{Gender})$ and a dependent variable Y (BIAQ). The idea is to determine the role of other variables, M: Private self-consciousness, public self-consciousness, depression, anxiety, age and IR, that intervene as mediators in the relationship between X and Y. The Baron and Kenny (1986) model which is based on a significant relationship between the independent variable and the dependent variable, was used for this. The total effect, significant coefficient $C$, a significant relationship of the mediator variables and the independent variable (significant $a$ effect) were estimated, and of 
them with the dependent variable (significant $b$ effect). The relationship between the independent variable and the dependent variable must be influenced by inclusion of the mediator variables in the regression up to the point where significance is lost (full mediation, $\left.C^{\prime}=0\right)$ or it decreases (partial mediation, $\left.C^{\prime} \neq 0\right)\left(C^{\prime}\right.$ less than the indirect effect $\left.a x b\right)$ (Ato and Vallejo, 2011). The Sobel test was applied to check that $C$ and $C$ ' are statistically different. This was possible because there were over 400 participants in the sample.

Multiple mediation analysis was performed by Monte Carlo resampling using a 99\% confidence interval and 10,000 iterations to calculate the indirect effect coefficient. The MEDIATE macro for the SPSS program version 22 was used to estimate the significance of the mediators and control any influence of covariates (http://www.afhayes.com/public/mediate.sps). All the analyses were accepted with at least $p<0.05$.

\section{Results}

\subsection{Descriptive and correlations}

Descriptive statistics and correlations of the study variables are shown in Table 1. The relationships of AO to the anxiety, depression, IR, private self-consciousness, and public selfconsciousness variables, as well as the BIAQ score were statistically significant. AE was significantly negatively correlated with anxiety, depression and IR, and positively with age and private self-consciousness. A comparison of means ( $t$ test) was done for Gender on the test factors employed in the study. Statistically significant differences were found for anxiety $t(659)=-2.36, \quad p<0.05$; private self-consciousness $t(467.72)=-5.29, \quad p<0.05$; public selfconsciousness $t(500.44)=-5.60, p<0.05$; AO $t(659)=-9.35, p<0.05 ;$ AE $t(659)=3.08, p<0.05$ and BIAQ $t(659)=-7.80, p<0.05$, but not depression $t(547.13)=1.81, p>0.05$. The age variable did not correlate with some variables (anxiety, public self-consciousness, and AO) and 
significant gender differences were observed $(t(518.08)=-5.53, p<0.05)$. Two age categories were used, mid (14-17 years) and late adolescence (18-21 years), for preliminary analyses before mediation. Gender-age 2x2 comparisons showed significant gender differences on the BIAQ scale $\left(F_{(1,660)}=5.085, p=0.024\right)$ and age in categories $\left(F_{(1,660)}=18.040, p=0.0001\right)$ with no interaction between these variables $(F=.117, p=0.735)$, considering IR, depression, $\mathrm{AO}$ and AE significant covariates (with partial $\eta^{2}$ effect sizes of 0.02 to 0.16 ). Participants in the 18-21-year age range showed a significantly higher average BIAQ in both women $(M=$ $24.41, S D=8.92)$ and men $(M=19.47, S D=7.89)$ compared to the $14-17$ age category in both women $(M=24.13, S D=9.15)$ and men $(M=18.18, S D=8.96)$. The age variable could have some role in the mediation model.

\section{-Insert Table 1-}

\subsection{Mediation analyses}

Multiple mediation analysis was done to study the mediating role of the IR, public selfconsciousness, private self-consciousness, depression, and age (quantitative variable) of the variables predicting Gender, $\mathrm{AO}, \mathrm{AE}$ and the BIAQ score variable. A multiple mediation analysis had been done previously with the variables mentioned and including anxiety, but it was decided to eliminate this variable from the model because it lost homogeneity. The Durbin-Watson index of independence of residuals was calculated as 1.97 , and as it was near 2 , the residuals were considered independent. With respect to normality, all the skewness indicators were below 3 and Kurtosis below 10, which are adequate, keeping in mind the sample size (Kline, 1998). The indicators of noncollinearity were also adequate, since the variance inflation factor is below 5 with tolerance levels between 0.575 y 0.974 .

-Insert Figure 1- 
Figure 1 shows the general mediation model where the statistically significant relationships of independent, mediator and dependent variables are represented. The results found suggest that IR, depressive symptomatology and age may be mediator variables in the relationship between Gender, dissatisfaction (AE) and concern (AO) about body image on behavioral impairment.

According to the model proposed by Baron and Kenny (1986), there would be mediation, because the following was observed: In the first place, the Gender, the $\mathrm{AO}$ and $\mathrm{AE}$ independent variables significantly influenced the BIAQ variable (total effect of Gender: $C=$ $0.12, p=0.000$; total effect AO: $C=0.38, p=0.000$; total effect AE: $C=-0.37, p=0.000)$. In the second place, the AO independent variable was related to all the mediators: IR, public self-consciousness, private self-consciousness, depression, and age $(p<0.01)$. The AE and Gender independent variables were significantly related to the IR, private self-consciousness, depression, and age variables (all with $p<0.01$, except Gender to the IR variable, which was hardly significant). Thirdly, the IR, depression and age mediator variables were significantly related to the BIAQ score variable $(p<0.01)$, but there was no relationship between the selfconsciousness scales (public and private) and BIAQ. Finally, the significance of the AO, AE and Gender variables was maintained as predictors of BIAQ when the mediator variables were included in the model, dashed lines in Figure 1 (direct effect of AO: $C^{\prime}=0.31, p=0.000$; direct effect AE: $C^{\prime}=-0.35, p=0.000$; direct effect Gender: $C^{\prime}=0.10, p=0.001$, which suggests that with these variables partial mediation is achieved. The Sobel test was statistically significant $(p<0.05)$ for AO relationships with IR (3.753), with depression (3.191), and age (-2.302); for AE with IR (-4.228), with depression (-4.565), and age (3.115); and for Gender with depression (-2.968), and age (3.837), but not with IR $(-1.791, p=0.073)$. Table 2 shows the $a x b$ effect of the independent variables (AO, AE and Gender) on 
mediators. Each of the variables intervening was homogeneous $p>0.05$ except age variable. The mediator variables mentioned explained $40.4 \%$ of the total effect.

-Insert Table 2-

\section{Discussion}

The purpose of this study was to analyze the relationships between concern for body image or Appearance Orientation (AO), dissatisfaction with body image or Appearance Evaluation (AE), and Gender with the behavioral impairments related to body image, keeping in mind the possible mediating roles of emotional symptomatology, self-consciousness, age (later included in the model as a mediating variable) and ideas of reference (IR).

The first hypothesis was partially corroborated in that it was expected to find a significant relationship between the independent and mediator variables. According to Baron and Kenny (1986) in addition to the starting relationship of the independent variables to the dependent variable, each independent variable ( $\mathrm{AO}, \mathrm{AE}$ and Gender) must be related through the mediators: IR, private self-consciousness, public self-consciousness, age, depression and anxiety. AO was the only variable which was related to all the mediator variables (higher presence of IR, higher private self-consciousness, public self-consciousness, age and depression). Although the anxiety variable showed a relationship with $\mathrm{AO}$ and $\mathrm{AE}$, and furthermore, had considerable $\beta$ weight, it had to be eliminated from the model because it lost homogeneity. This result is relevant, since $\mathrm{AO}$ is a variable with a stronger psychopathological relationship, unlike AE, which is considered a normal facet of character (Tantleff-Dunn and Lindner, 2011) (AE was also significantly related to IR in the sense that they showed more dissatisfaction with body image). IR, like social cognition, is a process in which attention is focused on a possible criticism or censuring by others, for example, but not only, for appearance (Lenzenweger et al., 1997; Meyer and Lenzenweger, 2009). Rosseret al. 
(2010) found that the individuals with strong concern for their body image, may interpret ambiguous stimuli as negative and related to their appearance, and therefore, reinforcing their concern. In our study, the relationship between high public self-consciousness and increase in IR in individuals worried about their body image is important, because it means biased processing of what happens around them is more severe when individuals are very worried about their body image. The striking role of IR as a potential mediator which is enabled when individuals are unsatisfied and worried about their body image is very relevant and less studied in the literature with respect to increasing impaired behavior related to body image.

The relationship between AE and depression is consistent with the results of other authors who have found a relationship between dissatisfaction with body image and depression, as well as anxiety (Stice and Shaw, 2002; Brechan and Kvalem, 2015).

Although no significant differences in gender were found in the comparisons of depression means, a significant relationship was found in this first step in the mediation calculation. Furthermore, it was the girls who showed higher private self-consciousness, and expectably, there was no difference between genders insofar as IR and public self-consciousness, as found by the authors of the scales (Lenzenweger et al., 1997; Scheier and Carver, 1985). Therefore, depressive symptomatology is a potential mediator variable which can influence both body image attitudes and in which gender has a relevant role.

According to Baron and Kenny (1986), the second hypothesis concerning the significant relationship of mediators to the dependent variable (behavioral impairment related to their body image) was partially confirmed since some mediator variables did not act as such. Specifically, there was no increase in private self-consciousness or public self-consciousness in those who showed the most behavioral impairment related to their body image (BIAQ), although previously public self-consciousness correlated with this variable, so either their 
relationship is not mediating, but a more direct relationship, or else the scores were not very high on what has been called self-absorption, more clearly pathological, in a sample of the general population (Ingram, 1990; Tellegen and Atkinson, 1974). Therefore, the only mediator variables related to the BIAQ were IR and depression (plus age was also included in the model). Other results along the same line have recently been found on this last variable. Brechan and Kvalem (2015) found that depressive symptomatology and low self-esteem mediate the relationship between dissatisfaction with body image in eating disorders.

The third hypothesis, concerning verification of a mediated relationship between independent and dependent variables, was again partly confirmed, since private selfconsciousness and public self-consciousness, did not act as mediators between the independent variables (AO, AE and Gender) and BIAQ. Depression, IR and age did participate as mediator variables. Focusing on the interval of confidence of the indirect effect, it is those who are worried about body image (AO) in particular who experience negative effects on body-image-related behavior provided that they are alerted to how others could judge their own appearance, thereby assuming augmented self-referencing (IR). Depressive symptomatology and gender (especially in women) are added to this as covariates mediating in the relationship. When they are dissatisfied with their body image (AE), the effects on body-image-related behavior must be mediated by depressive symptomatology and age (mainly in the older ones). Finally, the relationship between gender and behavioral impairments related to body image is mediated by depressive symptomatology in women and by age in men.

Adolescence is a sensitive period characterized by social stress, especially among the youngest (Fuhrmann et al., 2015; Romeo, 2013), as shown by the depressive symptomatology results. The inclusion of age in the model shows that it is a mediating variable connecting 
attitudes about body image (AO, $\mathrm{AE}$ ) and Gender with behavioral impairments related to body image. This variable was taken as a mediator in processes, a variable involving changes in maturation and coping, and not merely a chronological variable. Looking at the average scores, it may be observed that in the later years of adolescence (mainly the study period from 17-21 years) sensitivity to peer evaluation (IR) diminished (Blakemore and Mills, 2014). However, it is possible that behavioral impairments consolidate over the years, probably due to social pressure concerning perceived body image from the first years of adolescence. This model tentatively proposes that while some mediating variables relate attitudes about body image and Gender to behavioral impairments mainly in the youngest (as IR or emotional symptomatology), at later times in their development such body image-related behavioral impairments may become basically stabilized (Stice et al., 2010). This is particularly true for women and AO. The importance of variables such as IR and depressive symptomatology, because of their relationship to attitudes about appearance, make identification of individuals at risk valuable as a function of evolutionary development and social cognition. A crucial time in development would be from before around 17 years of age, when maladjustment indicators are found, and a point of inflection afterwards when certain negative attitudes about body image are consolidated. This complex moment in maturation seems to mediate along with other indicators (e.g., ideas of reference, depressive symptomatology) between attitudes toward body image and gender in deterioration of body-image-related behaviors.

Interestingly, according to Cash and Smolak (2011) concerning attitudes which must be present for a negative body image to develop, we found in a later analysis not presented in the results, that $7.26 \%$ of the young people in the sample scored high on $\mathrm{AO}$ and low on $\mathrm{AE}$ (stronger dissatisfaction with their body image), and 5.29\% in addition to showing these attitudes, had dysfunctional behavior related to their body image. Therefore, these data 
suggest the importance of detecting these problems in adolescence for early intervention and avoiding their chronicity or complication.

Body image dissatisfaction seems to follow a continuum of severity which would go from normal unhapiness to excessive fixation on appearance, which is manifested in behavioral disorders. Being able to identify the relationships with other psychopathological variables would help position the indiviual on that severity continuum and work with other problems not directly related to body image (such as depressive symptomatology and stronger selfreferencing) but which exert a negative influence on it. Brechan and Kvalem (2015) suggest that it would be of interest to widen the essential elements in intervention in body image disorders, not concentrating exclusively on its negative aspects. Continuing this idea, it would be of interest to consider age, depressive symptomatology and IR as indicators of severity to be kept in mind in directing intervention and follow-up, but especially, because as shown in this study, they are the key mediators.

Although this study provides interesting innovative results, they should be interpreted in the light of certain limitations. On one hand, this study did not follow a longitudinal design enabling causal relationships to be established among variables and is limited to their covariation and to participants in this study. Due to the use of a cross-sectional design (one measurement), it lacks the perspective of the subjects during their development that would enable observation of how their attitudes about body image, IR and depressive symptomatology evolve. This is of great interest in cases qualified as being of risk in the last analyses reported. In addition, the design includes the age variable and refers to different moments in the participants' evolution due to its wide range. This could be a limitation, but preliminary analyses showed importance suggesting the inclusion of this variable in the mediation model, even though in the final step it lost homogeneity of variance. In this sense, 
the analysis of mediator variables approaches the causal relationship approach (Hayes and Preacher, 2013), but this should be interpreted as strictly tentative as the design applied can only show relationships between variables. In any case, it could orient future research. The mediator variables should be checked to see whether there is any indication of change in behavior, habits, etc., prior to pathology that could guide possible early intervention, using this model, if it can be corroborated or replicated independently, since it gives clues to facets which should be kept very much in mind for the interview when AE, and especially AO are present. Another limitation of this study is that self-report scales were used with the known associated disadvantages, although they also have the advantage of directing the research and being very useful in detection or screening. Thus pathological indicator scales which are not self-reported, but rather rating-scales or interviews, should be used in addition to analyzing the role of self-absorption in this model. 


\section{References}

Adams, G.R., Abraham, K.G., Markstrom, C.A., 1987. The relations among identity development, self-Consciousness, and self-focusing during middle and late adolescence. Dev. Psychol. 23, 292-297.

Ato, M., Vallejo, G., 2011. Los efectos de terceras variables en la investigación psicológica. An. Psicol. 27, 550-561.

Banos, R.M., Belloch, A., Perpina, C., 1990. Self-consciousness scale: A study of Spanish housewives. Psychol. Rep. 66, 771-774.

Baron, R.M., Kenny, D.A., 1986. The moderator-mediator variable distinction in social psychological research: conceptual, strategic, and statistical considerations. J. Pers. Soc. Psychol. 51, 1173-1182. doi:10.1037/0022-3514.51.6.1173

Blakemore, S.-J., Mills, K.L., 2014. Is adolescence a sensitive period for sociocultural processing? Annu. Rev. Psychol. 65, 187-207. doi:10.1146/annurev-psych-010213115202

Brechan, I., Kvalem, I.L., 2015. Relationship between body dissatisfaction and disordered eating: mediating role of self-esteem and depression. Eat. Behav. 17, 49-58. doi:10.1016/j.eatbeh.2014.12.008

Brenner, K., Schmitz, N., Pawliuk, N., Fathalli, F., Joober, R., Ciampi, A., King, S., 2007. Validation of the English and French versions of the Community Assessment of Psychic Experiences (CAPE) with a Montreal community sample. Schizophr. Res. 95, 86-95. doi:10.1016/j.schres.2007.06.017

Carey, R.N., Donaghue, N., Broderick, P., 2014. Body image concern among Australian adolescent girls: The role of body comparisons with models and peers. Body Image 11, 81-84. doi:10.1016/j.bodyim.2013.09.006

Cash, T.F., 2000. User's manual for the Multidimensional Body-Self Relations Questionnaire. . Norfolk, VA: Old Dominion University [On-line]. Available from the author at www.body-images.com.

Cash, T.F., Fleming, E.C., 2002. The impact of body image experiences: Development of the body image quality of life inventory. Int. J. Eat. Disord. 31, 455-460. doi:10.1002/eat.10033

Cash, T.F., Smolak, L., 2011. Body Image: A Handbook of Science, Practice, and Prevention. Guilford Press, New York.

Delinsky, S.S., Wilson, G.T., 2006. Mirror exposure for the treatment of body image disturbance. Int. J. Eat. Disord. 39, 108-116. doi:10.1002/eat.20207

Dion, J., Blackburn, M.-E., Auclair, J., Laberge, L., Veillette, S., Gaudreault, M., Vachon, P., Perron, M., Touchette, É., 2015. Development and aetiology of body dissatisfaction in adolescent boys and girls. Int. J. Adolesc. Youth 20, 151-166. doi:10.1080/02673843.2014.985320

Elkind, D., Bowen, R., 1979. Imaginary audience behavior in children and adolescents. Dev. Psychol. 15, 38-44. doi:10.1037/0012-1649.15.1.38

Fuhrmann, D., Knoll, L.J., Blakemore, S.J., 2015. Adolescence as a Sensitive Period of Brain Development. Trends Cogn. Sci. 19, 558-566. doi:10.1016/j.tics.2015.07.008

Hayes, A.F., Preacher, K.J., 2013. Statistical mediation analysis with a multicategorical 
independent variable. Br. J. Math. Stat. Psychol. 451-470. doi:10.1111/bmsp.12028

Hollingshead, A.A., 1975. Five Factor Index of Social Position. Unpublished manuscript, Yale University, New Haven, CT.

Hughes, E.K., Gullone, E., 2011. Emotion regulation moderates relationships between body image concerns and psychological symptomatology. Body Image 8, 224-231. doi:10.1016/j.bodyim.2011.04.001

Ingram, R.E., 1990. Self-focused attention in clinical disorders: Review and a conceptual model. Psychol. Bull. 107, 156-176.

Lenzenweger, M.F., Bennett, M.E., Lilenfeld, L.R., 1997. The referential thinking scale as a measure of schizotypy: Scale development and initial construct validation. Psychol. Assess. 9, 452-463. doi:10.1037/1040-3590.9.4.452

Levine, M.P., Smolak, L., 2002. Body image development in adolescence, in: Cash, T.F., Pruzinsky, T. (Eds.), Body Image: A Handbook of Theory, Research and Clinical Practice. The Guilford Press, New York, pp. 74-82.

Littleton, H.L., Ollendick, T., 2003. Negative body image and disordered eating behavior in children and adolescents: What places youth at risk and how can these problems be prevented? Clin. Child Fam. Psychol. Rev. 6, 51-66. doi:10.1023/A:1022266017046

Lobo, A., Perez-Echeverria, M.J., Artal, J., 1986. Validity of the scaled version of the general health questionnaire (GHQ-28) in a Spanish population. Psychol. Med. 16, 135-140.

Markey, C.N., 2010. Invited Commentary: Why Body Image is Important to Adolescent Development. J. Youth Adolesc. 39, 1387-1391. doi:10.1007/s10964-010-9510-0

Meyer, E.C., Lenzenweger, M.F., 2009. The specificity of referential thinking: A comparison of schizotypy and social anxiety. Psychiatry Res. 165, 78-87. doi:10.1016/j.psychres.2007.10.015

Mitchell, S.H., Petrie, T.A., Greenleaf, C.A., Martin, S.B., 2012. Moderators of the internalization-body dissatisfaction relationship in middle school girls. Body Image 9, 431-440. doi:10.1016/j.bodyim.2012.07.001

Paxton, S.J., Neumark-Sztainer, D., Hannan, P.J., Eisenberg, M.E., 2006. Body dissatisfaction prospectively predicts depressive mood and low self-esteem in adolescent girls and boys. J. Clin. child Adolesc. Psychol. 35, 539-549. doi:10.1207/s15374424jccp3504_5

Peris-Mencheta Puch, L., Senin-Calderon, M.C., Fernandez-Jimenez, E., Fuentes-Marquez, S., Valdes-Diaz, M., Benitez-Hernandez, M.M., Rodriguez-Testal, J.F., 2011. Referential thinking and severe mental disorders. Eur. Psychiatry 26.

Pruzinsky, T., 2004. Enhancing quality of life in medical populations: a vision for body image assessment and rehabilitation as standards of care. Body Image 1, 71-81. doi:10.1016/S1740-1445(03)00010-X

Raich, R.M., Torras, J., Figueras, M., 1996. Estudio de la imagen corporal y su relación con el deporte en una muestra de estudiantes universitarios. Análisis y Modif. Conduct. 22 (85), 603-626.

Raine, A., 1991. The SPQ: A scale for the assessment of schizotypal personality based on DSM-III-R criteria. Schizophr. Bull. 17, 555-564.

Rodríguez-Testal, J.F., 2013. Alteraciones de la imagen corporal. Síntesis, Madrid.

Romeo, R.D., 2013. The Teenage Brain: The Stress Response and the Adolescent Brain. Curr. Dir. Psychol. Sci. 22, 140-145. doi:10.1177/0963721413475445 
Rosen, J.C., Srebnik, D., Saltzberg, E., Wendt, S., 1991. Development of a Body Image Avoidance Questionnaire. Psychol. Assess. 3, 32-37.

Rosser, B.A., Moss, T., Rumsey, N., 2010. Attentional and interpretative biases in appearance concern: An investigation of biases in appearance-related information processing. Body Image 7, 251-254. doi:10.1016/j.bodyim.2010.02.007

Scheier, M.F., Carver, C.S., 1985. The Self-Consciousness Scale: a revised version for use with general populations. J. Appl. Soc. Psychol. 15, 687-699. doi:10.1111/j.15591816.1985.tb02268.x

Senín-Calderón, C., Rodríguez-Testal, J.F., Fernández-Jiménez, E., Valdés-Diaz, M., BenítezHernández, M.M., Fuentes-Márquez, S., Valdés-Díaz, M., 2010. Reliability and validity of the ref scale for referential thinking. Eur. Psychiatry Suppl. 1, 758. doi:10.1016/S0924-9338(10)70755-0

Senín-Calderón, M.C., Rodríguez-Testal, J.F., Perona-Garcelán, S., 2014. Referential thinking: Psychopathological and developmental aspects [El pensamiento referencial: aspectos psicopatológicos y del desarrollo], First Edit. ed. CreateSpace Independent Publishing Platform, Charleston, SC.

Smolak, L., 2011. Body image development in childhood, in: Cash, T.F., Smolak, L. (Eds.), Body Image : A Handbook of Science, Practice, and Prevention. The Guilford Press, New York, pp. 67-75.

Stice, E., Marti, C.N., Durant, S., 2011. Risk factors for onset of eating disorders: Evidence of multiple risk pathways from an 8-year prospective study. Behav. Res. Ther. 49, 622-627. doi:10.1016/j.brat.2011.06.009

Stice, E., Marti, C.N., Shaw, H., Jaconis, M., 2010. An 8-year longitudinal study of the natural history of threshold, subthreshold and partial eating disorders from a community sample of adolescents. J. Abnorm. Psychol. 118, 587-597. doi:10.1037/a0016481.An

Stice, E., Shaw, H.E., 2002. Role of body dissatisfaction in the onset and maintenance of eating pathology: A synthesis of research findings. J. Psychosom. Res. 53, 985-993. doi:10.1016/S0022-3999(02)00488-9

Tantleff-Dunn, S., Lindner, D.M., 2011. Body image and social functioning, in: Cash, T.F., Smolak, L. (Eds.), Body Image : A Handbook of Science, Practice, and Prevention. The Guilford Press, New York, pp. 263-270.

Tellegen, a, Atkinson, G., 1974. Openness to absorbing and self-altering experiences ("absorption"), a trait related to hypnotic susceptibility. J. Abnorm. Psychol. 83, 268277. doi:10.1037/h0036681

Vartanian, L.R., Dey, S., 2013. Self-concept clarity, thin-ideal internalization, and appearance-related social comparison as predictors of body dissatisfaction. Body Image 10, 495-500. doi:10.1016/j.bodyim.2013.05.004

Wong, G.H.Y., Hui, C.L.M., Tang, J.Y.M., Chiu, C.P.Y., Lam, M.M.L., Chan, S.K.W., Chang, W.C., Chen, E.Y.H., 2012. Screening and assessing ideas and delusions of reference using a semi-structured interview scale: A validation study of the Ideas of Reference Interview Scale (IRIS) in early psychosis patients. Schizophr. Res. 135, 158163. doi:10.1016/j.schres.2011.12.006 


\section{Tables}

Table 1. Descriptive statistics and correlations

\begin{tabular}{|c|c|c|c|c|c|c|c|c|c|}
\hline & 1 & 2 & 3 & 4 & 5 & 6 & 7 & 8 & 9 \\
\hline 1.Age & - & & & & & & & & \\
\hline 2.Anxiety & -0.008 & - & & & & & & & \\
\hline 3.Depression & $-\bar{l}-126^{* *}$ & $0.533^{* *}$ & - & & & & & & \\
\hline 4.IR & $0.289 * *$ & $0.341^{* *}$ & $0.344 * *$ & - & & & & & \\
\hline 5.PrivateSC & $0.214^{* *}$ & $0.244 * *$ & $0.128^{* *}$ & $0.185^{* *}$ & - & & & & \\
\hline 6.PublicSC & -0.009 & $0.211 * *$ & $0.136^{* *}$ & $0.286^{* *}$ & $0.533^{* *}$ & - & & & \\
\hline 7.AO & -0.021 & $0.231 * *$ & $0.135^{* *}$ & $0.306^{* *}$ & $0.265^{* *}$ & $0.595^{* *}$ & - & & \\
\hline 8. $\mathrm{AE}$ & $0.125^{* *}$ & 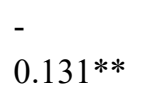 & $\begin{array}{l}- \\
0.171^{* *}\end{array}$ & $\begin{array}{l}- \\
0.120^{* *}\end{array}$ & $0.077^{*}$ & -0.030 & -0.024 & - & \\
\hline 9. BIAQ & $0.088^{*}$ & $0.336^{* *}$ & $0.281^{* *}$ & $0.299 * *$ & $0.197 * *$ & $0.300^{* *}$ & $0.432 * *$ & $-\overline{0.391 * *}$ & - \\
\hline $\mathrm{M}(\mathrm{SD})$ men & $\begin{array}{l}16.51 \\
(1.90)\end{array}$ & $\begin{array}{l}4.84 \\
(3.80)\end{array}$ & $\begin{array}{l}2.51 \\
(3.76)\end{array}$ & $\begin{array}{l}7.65 \\
(5.31)\end{array}$ & $\begin{array}{l}20.14 \\
(6.07)\end{array}$ & $\begin{array}{l}16.26 \\
(4.82)\end{array}$ & $\begin{array}{l}3.28 \\
(0.57)\end{array}$ & $\begin{array}{l}3.38 \\
(0.74)\end{array}$ & $\begin{array}{l}18.39 \\
(8.79)\end{array}$ \\
\hline $\mathrm{M}(\mathrm{SD})$ women & $\begin{array}{l}17.47 \\
(2.46)\end{array}$ & $\begin{array}{l}5.62 \\
(4.01)\end{array}$ & $\begin{array}{l}1.98 \\
(2.99)\end{array}$ & $\begin{array}{l}8.21 \\
(5.48)\end{array}$ & $\begin{array}{l}22.71 \\
(5.22)\end{array}$ & $\begin{array}{l}18.44 \\
(4.27)\end{array}$ & $\begin{array}{l}3.71 \\
(0.53)\end{array}$ & $\begin{array}{l}3.18 \\
(0.78)\end{array}$ & $\begin{array}{l}24.25 \\
(9.05)\end{array}$ \\
\hline $\begin{array}{l}M(S D) \\
14-17 \text { years }\end{array}$ & & $\begin{array}{l}5.37 \\
(3.85)\end{array}$ & $\begin{array}{l}2.47 \\
(3.46)\end{array}$ & $\begin{array}{l}9.01 \\
(5.33)\end{array}$ & $\begin{array}{l}20.28 \\
(5.61)\end{array}$ & $\begin{array}{l}17.75 \\
(4.77)\end{array}$ & $\begin{array}{l}3.58 \\
(0.56)\end{array}$ & $\begin{array}{l}3.19 \\
(0.79)\end{array}$ & $\begin{array}{l}21.64 \\
(9.52)\end{array}$ \\
\hline $\begin{array}{l}\mathrm{M}(\mathrm{SD}) \\
18-21 \text { years }\end{array}$ & & $\begin{array}{l}5.29 \\
(4.16)\end{array}$ & $\begin{array}{l}1.47 \\
(2.67)\end{array}$ & $\begin{array}{l}6.06 \\
(5.09)\end{array}$ & $\begin{array}{l}23.65 \\
(5.21)\end{array}$ & $\begin{array}{l}17.70 \\
(4.11)\end{array}$ & $\begin{array}{l}3.53 \\
(0.60)\end{array}$ & $\begin{array}{l}3.33 \\
(0.71)\end{array}$ & $\begin{array}{l}23.61 \\
(8.94)\end{array}$ \\
\hline
\end{tabular}

Note. Anxiety= Goldberg General Health Questionnaire (GHQ); Depression= GHQ; IR= Ideas of Reference, REF; PrivateSC $=$ Private self-consciousness, $R$-SCS; PublicSC $=$ Public self-consciousness, $R-S C S ; \mathrm{AO}=$ Appearance Orientation, $M B S R Q ; \mathrm{AE}=$ Appearance Evaluation, MBSRQ; $\mathrm{BIAQ}=$ Behavioral disorders related to body image.

$* * p<0.01$

${ }^{*} p<0.05$ 
Table 2. Total indirect effects for the three mediators

\begin{tabular}{|c|c|c|c|c|}
\hline & B & s.e & LLCI & ULCI \\
\hline \multicolumn{5}{|c|}{ Indirect effects through IR } \\
\hline Gender & -0.012 & 0.006 & -0.026 & 0.000 \\
\hline $\mathrm{AO}$ & 0.049 & 0.013 & 0.025 & 0.077 \\
\hline $\mathrm{AE}$ & -0.018 & 0.007 & -0.034 & 0.006 \\
\hline
\end{tabular}

Indirect effects through Depression

Gender

$-0.024$

0.008

$-0.041$

$-0.010$

$\mathrm{AO}$

0.027

0.008

0.012

0.046

$\mathrm{AE}$

$-0.027$

0.008

$-0.045$

$-0.012$

Indirect effects through Public SC

Gender

0.000

0.001

$-0.003$

0.003

$\mathrm{AO}$

0.000

0.025

$-0.049$

0.050

$\mathrm{AE}$

0.000

0.001

$-0.003$

0.003

Indirect effects through Private SC

Gender

0.005

0.006

$-0.006$

0.018

$\mathrm{AO}$

0.007

0.008

$-0.008$

0.024 

$\mathrm{AE}$
0.003
0.004
$-0.004$
0.013

Indirect effect through Age

Gender

0.041

0.010

0.022

0.064

$\mathrm{AO}$

$-0.018$

0.007

$-0.035$

0.004

$\mathrm{AE}$

0.026

0.008

0.011

0.043

Note: $\beta=$ non-standardized coefficient. s.e: standard error. A confidence interval (LLCI-

ULCI) not containing zero indicates a significant mediation for the mediator and independent variable, controlling for all other mediators and independent variables.

Depression= Goldberg General Health Questionnaire (GHQ); IR=Ideas of Reference, REF;

Private $\mathrm{SC}=$ Private self-consciousness, $R$-SCS; Public SC=Public self-consciousness, $R$ SCS; $\mathrm{AO}=$ Appearance Orientation, $M B S R Q ; \mathrm{AE}=$ Appearance Evaluation, $M B S R Q$. 


\section{Figures}

Figure 1. Multiple mediation model of BIAQ

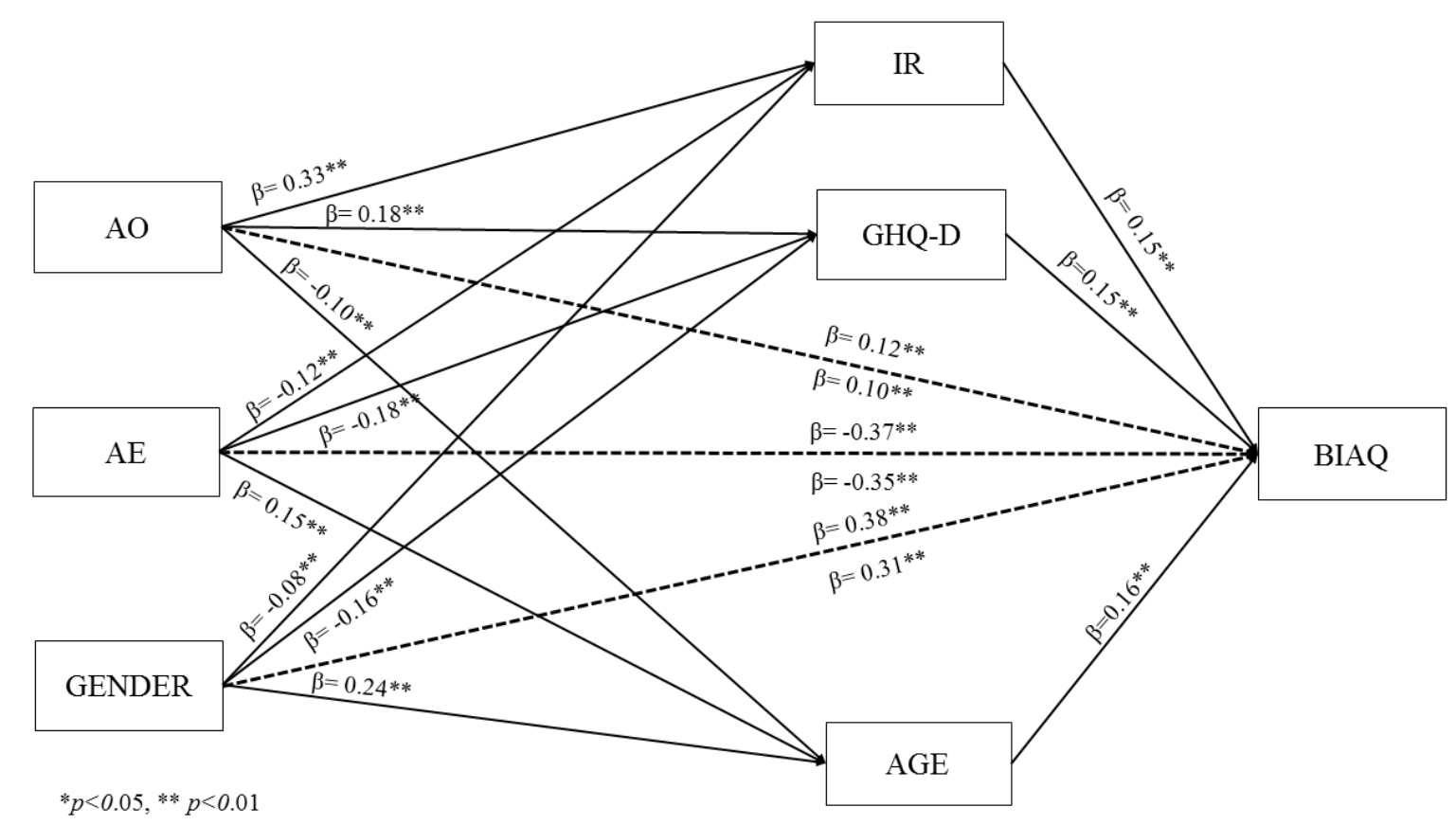

Note: Because of the complexity of the model, only mediator variables significant when effects are significant in $a, b$ and $a \times b$ have been included. $\beta=$ non-standardized coefficient. $I R=I d e a s$ of Reference, REF; Depression= Goldberg General Health Questionnaire (GHQ); Age $=$ quantitative variable; $\mathrm{AO}=$ Appearance Orientation, $M B S R Q ; \mathrm{AE}=$ Appearance Evaluation, MBSRQ; $\mathrm{BIAQ}=$ Behavioral disorders related to body image. Solid line: direct effects; dashed line: indirect effects or mediation. 